\title{
RADIOCARBON DATING OF CALCINED BONES: WHERE DOES THE CARBON COME FROM?
}

\author{
A Zazzo $^{1} \bullet \mathrm{J}-\mathrm{F}$ Saliège $\mathrm{e}^{1,2} \cdot \mathrm{A} \mathrm{Person}^{3} \cdot \mathrm{H} \mathrm{Boucher}^{4}$
}

ABSTRACT. Over the past decade, radiocarbon dating of the carbonate contained in the mineral fraction of calcined bones has emerged as a viable alternative to dating skeletal remains in situations where collagen is no longer present. However, anomalously low $\delta^{13} \mathrm{C}$ values have been reported for calcined bones, suggesting that the mineral fraction of bone is altered. Therefore, exchange with other sources of carbon during heating cannot be excluded. Here, we report new results from analyses on cremated bones found in archaeological sites in Africa and the Near East, as well as the results of several experiments aiming at improving our understanding of the fate of mineral and organic carbon of bone during heating. Heating of modern bone was carried out at different temperatures, for different durations, and under natural and controlled conditions, and the evolution of several parameters (weight, color, $\% \mathrm{C}, \% \mathrm{~N}, \delta^{13} \mathrm{C}$ value, carbonate content, crystallinity indexes measured by XRD and FTIR) was monitored. Results from archaeological sites confirm that calcined bones are unreliable for paleoenvironmental and paleodietary reconstruction using stable isotopes. Experimental results suggest that the carbon remaining in bone after cremation likely comes from the original inorganic pool, highly fractionated due to rapid recrystallization. Therefore, its reliability for ${ }^{14} \mathrm{C}$ dating should be seen as close to that of tooth enamel, due to crystallographic properties of calcined bones.

\section{INTRODUCTION}

Collagen, the organic fraction of bone, is routinely used to date skeletal remains. This is mainly for 2 reasons. First, collagen concentrates most (95\%) of a bone's carbon, which considerably reduces the sample size required for a ${ }^{14} \mathrm{C}$ date. Second, the carbon present in the mineral fraction of bone (carbonate apatite, or bioapatite) is considered prone to diagenetic alteration due to the small size of bone crystallites, which makes them thermodynamically unstable and likely to incorporate dissolved carbonates from the environment during recrystallization (Haynes et al. 1968; Hassan et al. 1977; Schoeninger and DeNiro 1982). Therefore, the reliability of ${ }^{14} \mathrm{C}$ dates obtained on bone bioapatite has always been questioned and very few dates have been published. In arid and semi-arid regions, however, collagen is not preserved and carbonate in bioapatite is the only source of carbon remaining for radiocarbon dating. Moreover, recent work using microfiltration has shown that obtaining "clean" collagen, free of external sources of carbon, is not as straightforward as previously thought (Bronk Ramsey et al. 2004; Higham et al. 2006; Hüls et al. 2007). This is why the possibility of using bone carbonate was reconsidered in the mid-1990s (Saliège et al. 1995). Their approach proved successful in arid environments, or in sites where bones were protected from chemical exchange with the surrounding environments, as in the case of burials.

Another strategy is to date cremated bones. Lanting et al. (2001) showed that cremated bones (i.e. bones exposed to temperature $>600{ }^{\circ} \mathrm{C}$ ) produced reliable ${ }^{14} \mathrm{C}$ dates and were very resistant to external influences due to recrystallization during heating. From a crystallographic and structural point of view, bone apatite becomes very similar to enamel apatite after cremation. Experimental heating of modern bones showed that bone organic matter is decomposed at low temperature (around 300-350 ${ }^{\circ} \mathrm{C}$ ), and bone crystals become larger, better structured, and more densely packed when the temperature reaches $>600{ }^{\circ} \mathrm{C}$, which protects them from further exchange with diagenetic fluids (Person et al. 1996; Munro et al. 2007). This is the reason invoked to explain why cremated bones can provide

\footnotetext{
${ }^{1}$ Muséum national d'Histoire naturelle, CNRS UMR 7209 “Archéozoologie, Archéobotanique: Sociétés, Pratiques et Environnements," CP 56, 55 rue Buffon, F-75005 Paris, France. Corresponding author. Email: zazzo@mnhn.fr.

${ }^{2}$ Université Pierre et Marie Curie, LOCEAN, 4 place Jussieu, 75252 Paris cedex 05, France.

${ }^{3}$ Université Pierre et Marie Curie, JE 2477 Biominéralisations et Paléoenvironnements, 4 place Jussieu, 75252 Paris cedex 05, France.

${ }^{4}$ IRD, UR055 Paléotropique, 32 avenue Henri Varagnat, 93143 Bondy cedex, France.
}

(C) 2009 by the Arizona Board of Regents on behalf of the University of Arizona

Proceedings of the 5th International ${ }^{14} \mathrm{C}$ and Archaeology Symposium, edited by Irka Hajdas et al.

RADIOCARBON, Vol 51, Nr 2, 2009, p 601-611 
reliable ${ }^{14} \mathrm{C}$ dates. To the archaeological community, this method was a breakthrough because cremation is a relatively common burial practice and cremated bones were considered undatable because of their lack of collagen.

Whereas $\delta^{13} \mathrm{C}$ values of charred bones remain unchanged, cremation at higher temperatures was found to cause a sharp (4-10\%o) decrease in apatite $\delta^{13} \mathrm{C}$ values, in association with a loss of $>75 \%$ of bone structural carbonate (Lanting et al. 2001, data not shown; van Strydonck et al. 2005; Olsen et al. 2008). The mechanism responsible for this isotope shift remains unclear as laboratory experiments show contradicting evidence. Van Strydonck et al. (2005) reported lower $\delta^{13} \mathrm{C}$ values for bones heated at 700 and $980{ }^{\circ} \mathrm{C}$, similar to what is found in archaeological bone samples, whereas Munro et al. (2008) found a 5\%o increase in $\delta^{13} \mathrm{C}$ values of bone carbonate between 650 and $725^{\circ} \mathrm{C}$. Because the structure of bone apatite is altered, chemical exchange with the environment during or just after heating is possible and the residual carbon does not necessarily come from carbonate initially present in the bone. Potentially, 3 external sources of carbon are available for exchange: from atmospheric $\mathrm{CO}_{2}$, from bone organic matter (collagen), or from $\mathrm{CO}_{2}$ produced by the combustion of wood. Exchange with carbon coming from collagen or combusted fuel could have implications for the apparent age of cremated bone and make it appear older than it actually is. Because collagen is derived from protein only, whereas apatite represents the average diet, the "reservoir effect" is thought to be more important in collagen than in apatite (Olsen et al. 2008). If carbon from collagen can exchange with bone carbonate, the "reservoir effect" recorded in the collagen from populations relying on marine resources could then be transferred to bone apatite. Similarly, if carbon from wood combustion can exchange with bone carbonate, the "old wood" effect could be transferred to bone and would not necessarily be detected with comparison between bone and charcoal.

This paper aims to determine the origin of carbon present in carbonate from calcined apatite. To address this question, we present new data from archaeological calcined bones in $\mathrm{C}_{3}$ and $\mathrm{C}_{4}$ contexts, and report the results of several experiments carried out under controlled and natural conditions. Stable isotope values of charred and calcined bones were measured and related to the chemical and crystallographic changes monitored during heating.

\section{MATERIAL AND METHODS}

\section{Archaeological Samples}

Cremated bones from several archaeological sites in Africa (Chin Tafidet in Niger, Mankhor in Algeria) and the Near East (Tell Shyukh Fawqani, Syria) were selected, ranging in age from the 1st to the 4th millennium BC. A previous study (Saliège, unpublished data) showed that animals and humans in Chin Tafidet and Mankhor relied on $\mathrm{C}_{4}$ plants, or $\mathrm{C}_{4}$-eating animals, whereas in Syria, humans relied on $\mathrm{C}_{3}$ biomass. For each bone, a pair of samples was selected: non-cremated (or charred) and calcined bone (white in color). Prior to geochemical and spectroscopic analyses, powdered samples were pretreated with $1 \mathrm{M}$ acetic acid under vacuum overnight in order to remove secondary calcite (Balter et al. 2002). Samples were then rinsed several times in distilled water and oven-dried at $60{ }^{\circ} \mathrm{C}$.

\section{Modern Samples}

Modern samples include bones collected from a cow (Bos taurus) and a pig (Sus scrofa) raised in France and slaughtered in 2007, as well as the mandible of a moose (Alces alces) collected in Saskatchewan (Canada) in 2004. The cow and pig bones were first oven-cooked then put on the embers of a fire for $1 \mathrm{hr}$ to mimic natural conditions. The moose jaw was cleaned and cut in small sections of 0.5 to $1 \mathrm{~g}$ each using a saw. These samples were then used for our laboratory experiments. 


\section{Experimental}

Three laboratory experiments were designed, with increasing levels of control on environmental parameters. In the first series of experiments (Experiment A1 and A2), different aliquots of the same bone were heated in the presence of air in a programmable tubular furnace (Hermann Moritz, West 2068 model) between 100 and $1000{ }^{\circ} \mathrm{C}$. In Experiment A1, the furnace was programmed at the target temperature and each bone sample was left in it for $1 \mathrm{hr}$. In Experiment A2, the furnace was at room temperature at the beginning of the experiment before it was heated to the target temperature. Samples were left in the furnace for $3 \mathrm{hr}$. The second experiment (Experiment B) aimed to test whether organic matter had an affect on carbonate $\delta^{13} \mathrm{C}$ values. Bone organic matter was first removed by thermal decomposition before cremation under natural condition. To achieve complete removal of bone organic matter without altering the structure of bone apatite, the sample was first heated in a programmable tubular furnace for $1 \mathrm{hr}$ at $300{ }^{\circ} \mathrm{C}$ to decompose collagen, then heated at $450{ }^{\circ} \mathrm{C}$ in the presence of oxygen $(\mathrm{P}=1 \mathrm{~atm})$ for $20 \mathrm{hr}$ to oxidize the leftover carbon. Finally, the organic-matter-free bone sample was calcined in a fire for $1 \mathrm{hr}$ similar to our natural experiments. In the third series of experiments (Experiment $\mathrm{C}$ ), the composition of the atmosphere during cremation was controlled. First, bone organic matter was removed using the same method as in Experiment B. Organic-free bone samples were heated at $800^{\circ} \mathrm{C}$ for $5 \mathrm{~min}$ in sealed quartz tubes (a) under vacuum; (b) in the presence of $\mathrm{O}_{2}$ only; (c) in the presence of $\mathrm{CO}_{2}$ only; and (d) in the presence of a $\mathrm{O}_{2}+\mathrm{CO}_{2}$ mixture in various proportions. In order to test for isotope exchange during cremation, we used 2 isotopically distinct $\mathrm{CO}_{2}$ sources: $\mathrm{CO}_{2}$ from a tank $\left(\delta^{13} \mathrm{C}=-41.1 \%\right.$ o $)$ and $\mathrm{CO}_{2}$ derived from our internal calcite standard $\left(\delta^{13} \mathrm{C}=+2.1 \%\right.$ ) .

\section{Analytical Methods}

The color, remaining weight after heating, crystallinity index, splitting factor, carbon and nitrogen percent, carbonate content, and carbon isotope composition of the heated samples were measured. Carbon and nitrogen contents were determined using a CHNOS elemental analyzer (Elementar vario EL III). Precision for $\mathrm{C}$ and $\mathrm{N}$ was better than $\pm 0.1 \%$. Bone carbonate ${ }^{13} \mathrm{C} /{ }^{12} \mathrm{C}$ ratios were measured on an Isoprime isotope ratio mass spectrometer through a continuous-flow inlet system using an Isoprime Multiflow interface. Precision on the carbon isotope value $\left(\delta^{13} \mathrm{C}\right)$ was $\pm 0.03 \%$ o $(1 \sigma)$, based on repeated analysis of our internal calcite standard. Carbonate contents were estimated by measuring the pressure of $\mathrm{CO}_{2}$ evolved from the bone sample during the acid reaction with the transducer of the mass spectrometer and by comparing it to the calibration curve established based on the calcite internal standard. Precision was $\pm 0.2 \%(1 \sigma)$. XRD analysis of bone powder was performed on a diffractometer (Siemens D500) as described in Person et al. (1995). The crystallinity index (CI) was measured as defined by Person et al. (1995). CI usually varies between 0 for a modern bone and 1.25 for bones exposed at high temperatures (Munro et al. 2007). FTIR analysis was performed on a Bruker IFS Equinox 55 FTIR spectrometer as described in Bertaux et al. (1998), with an instrumental resolution of $2 \mathrm{~cm}^{-1}$. We used the splitting factor (SF) as defined by Shemesh (1990) as a proxy of the crystallinity of bone apatite. SF usually varies between 2.5 for a modern bone and 5 for bones exposed at high temperatures (Munro et al. 2007).

\section{RESULTS}

\section{Archaeological Bones}

Table 1 presents the elemental composition, $\delta^{13} \mathrm{C}$ values, and splitting factor (SF) measured on the archaeological material analyzed in this study. The $\delta^{13} \mathrm{C}$ values are plotted with previously published results (Figure 1). The non-cremated or charred (black) bones from the Sahara region have 
$\delta^{13} \mathrm{C}$ values between 0 and $-3 \%$, which are typical of a $\mathrm{C}_{4}$-based diet, whereas the calcined (white) portion from the same bones/individuals have much lower $\delta^{13} \mathrm{C}$ values, between -4 and $-16 \%$ o (Figure 1A). Intrabone isotope differences range between 3 and $15.5 \%$. The non-cremated bone from Syria has a value of $-11.2 \%$, showing a predominantly $\mathrm{C}_{3}$-based diet. The 2 calcined bones from the same site have $\delta^{13} \mathrm{C}$ values of 8 to $15 \%$ o lower and plot between -19 and $-27 \%$, which are within the range of published values for calcined bones found in $\mathrm{C}_{3}$ context (Figure 1B). High SF values (between 7.6 and 9.4) were found for cremated bones. These values are higher than those previously published for apatites recrystallized at high temperatures (Munro et al. 2007), probably as a result of a higher instrumental resolution.

Table 1 Results from archaeological cremated bones found in $\mathrm{C}_{3}$ and $\mathrm{C}_{4}$ contexts.

\begin{tabular}{|c|c|c|c|c|c|c|c|c|}
\hline Sample \# & Taxon & Location & Age & Color & $\begin{array}{l}\mathrm{C} \\
(\mathrm{wt} \%)\end{array}$ & $\begin{array}{l}\mathrm{N} \\
(\mathrm{wt} \%)\end{array}$ & $\begin{array}{l}\delta^{13} \mathrm{C} \\
(\% o)\end{array}$ & $\begin{array}{l}\text { SF } \\
\text { FTIR } \\
\end{array}$ \\
\hline \multirow[t]{2}{*}{ TSF 104} & Homo & Tell Shyukh & 1st mill. BC & not cremated & & & -11.2 & \\
\hline & sapiens & Fawqani, Syria & & white & 0.4 & 0.0 & -19.4 & 9.4 \\
\hline TSF 2516 & $\begin{array}{l}\text { Homo } \\
\text { sapiens }\end{array}$ & $\begin{array}{l}\text { Tell Shyukh } \\
\text { Fawqani, Syria }\end{array}$ & 1st mill. BC & white & & & -26.4 & \\
\hline CT & $\begin{array}{l}\text { Homo } \\
\text { sapiens }\end{array}$ & $\begin{array}{l}\text { Chin Tafidet, } \\
\text { Niger }\end{array}$ & $\begin{array}{l}\text { 2nd-3rd } \\
\text { mill. BC }\end{array}$ & $\begin{array}{l}\text { not cremated } \\
\text { white }\end{array}$ & 1.8 & 0.6 & $\begin{array}{r}-2.7 \\
-15.0\end{array}$ & \\
\hline \multirow[t]{2}{*}{ MkhrT1 } & Bos taurus & Mankhor, Algeria & 4th mill. BC & black & 3.0 & 0.4 & -1.0 & \\
\hline & & & & white & 0.6 & 0.1 & -8.1 & 7.6 \\
\hline \multirow[t]{2}{*}{ MkhrR2 } & Bos taurus & Mankhor, Algeria & 4th mill. BC & black & 2.1 & 0.3 & -0.5 & \\
\hline & & & & white & 0.5 & 0.3 & -13.4 & 8.2 \\
\hline \multirow[t]{2}{*}{ MkhrH1sup } & Bos taurus & Mankhor, Algeria & 4th mill. BC & gray & 0.5 & 0.3 & -1.4 & \\
\hline & & & & white & 0.6 & 0.6 & -16.9 & 8.5 \\
\hline AA1 & Bos taurus & Mankhor, Algeria & 4th mill. BC & $\begin{array}{l}\text { not cremated } \\
\text { white }\end{array}$ & 0.4 & 0.0 & $\begin{array}{l}-1.1 \\
-4.0\end{array}$ & \\
\hline H1inf & Bos taurus & Mankhor, Algeria & 4th mill. BC & $\begin{array}{l}\text { not cremated } \\
\text { white }\end{array}$ & 0.9 & 0.0 & $\begin{array}{l}-1.4 \\
-9.0\end{array}$ & \\
\hline
\end{tabular}

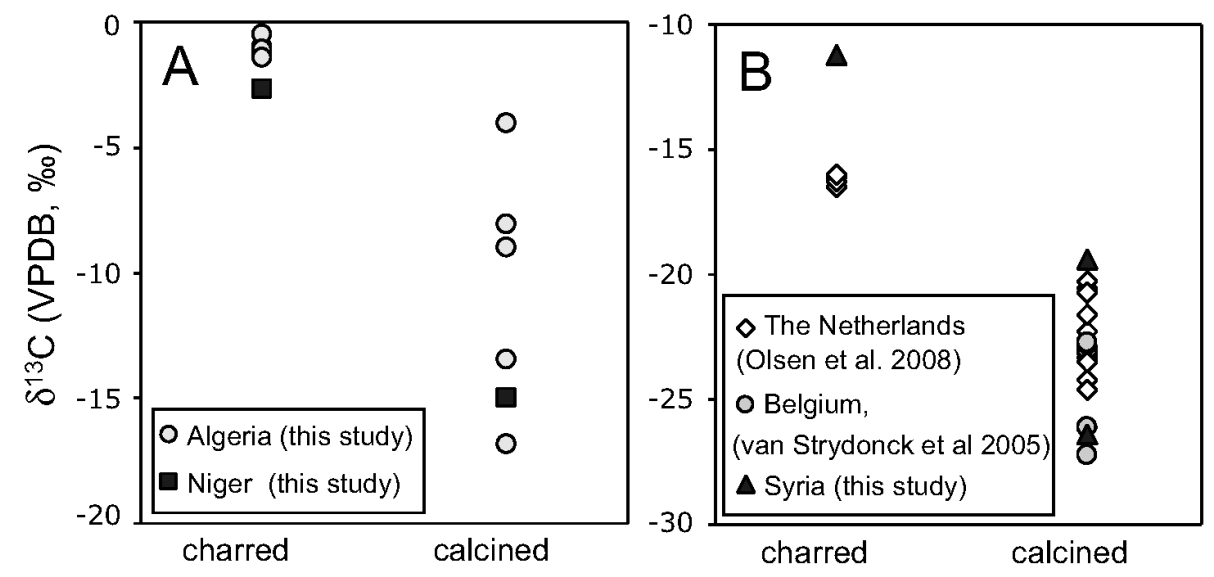

Figure 1 Carbon isotope values from charred and calcined archaeological bones in $\mathrm{C}_{4}(\mathrm{~A})$ and $\mathrm{C}_{3}$ contexts (B)

\section{Natural Experiments}

Results from the 2 modern bones heated in natural conditions are presented in Table 2. The nitrogen contents of the charred portions of bones (black in color) are lower than for fresh bone, suggesting that collagen degradation has already started. Crystallinity index $(\mathrm{CI})(<0.1)$ and splitting factor (SF) 
(<4) values are close to that of non-cremated bones (Person et al. 1996; Munro et al. 2007) and suggest very little crystallographic rearrangement. This is independently confirmed by carbonate contents comprised between 4.6 and $6.1 \%$, which is typical of that of bone apatite. $\delta^{13} \mathrm{C}$ values of charred bones are between -16 and $-18 \%$, which is at the lower end of the range for $\mathrm{C}_{3}$ feeders. The calcined portions of the same bones (white in color) have lower $\mathrm{C}$ contents $(<1.0 \%)$ and no nitrogen left, showing that degradation of bone organic matter is complete. High CI (>1) and high SF (>5) values, as well as low carbonate contents $(<4 \%)$, show that recrystallization has taken place. Finally, low $\delta^{13} \mathrm{C}$ values (between -23 and $-25 \%$ ) were measured. These values fall within the range of values measured for calcined bones found in $C_{3}$ contexts (Van Strydonck et al. 2005; Olsen et al. 2008) and demonstrate that the new isotope signature is acquired rapidly, probably during the cremation process itself.

Table 2 Color, percent of carbon and nitrogen, carbonate content, $\delta^{13} \mathrm{C}$ values, CI (XRD), and SF (FTIR) values measured on a pig bone and on a bovine bone heated in a fire to mimic "natural" conditions.

\begin{tabular}{lllllllllll}
\hline $\begin{array}{l}\text { Sample } \\
\#\end{array}$ & Taxon & Location & Age & Color & $\begin{array}{l}\mathrm{C} \\
\text { (wt\%) }\end{array}$ & $\begin{array}{l}\mathrm{N} \\
(\mathrm{wt} \%)\end{array}$ & $\begin{array}{l}{\left[\mathrm{CO}_{3}{ }^{2-}\right]} \\
(\mathrm{wt} \%)\end{array}$ & $\begin{array}{l}\delta^{13} \mathrm{C} \\
(\%)\end{array}$ & $\mathrm{CI}$ & $\mathrm{SF}$ \\
\hline CSM2 & \multirow{2}{*}{ Sus scrofa } & Lorraine, France & modern & black & 16.6 & 2.4 & 4.6 & -18.2 & 0.09 & 3.4 \\
CSM1 & & & & white & 0.9 & 0.1 & 3.8 & -23.2 & 1.24 & 7.9 \\
SAR2 & \multirow{2}{*}{ Bos taurus } & \multirow{2}{*}{ Sarthe, France } & \multirow{2}{*}{ modern } & black & 6.0 & 1.0 & 6.1 & -16.2 & 0.07 & 3.7 \\
SAR1 & & & & white & 0.7 & 0.0 & 2.0 & -24.5 & 1.27 & 5.0 \\
\hline
\end{tabular}

\section{Laboratory Experiments}

Results from Experiments A1 and A2 are summarized in Table 3 and presented in Figures 2 and 3. Evolution of color, $\mathrm{C} / \mathrm{N}$ content, $\left[\mathrm{CO}_{3}{ }^{2-}\right], \delta^{13} \mathrm{C}, \mathrm{CI}$, and $\mathrm{SF}$ values were monitored between 100 and $1000{ }^{\circ} \mathrm{C}$ at 50 to $100{ }^{\circ} \mathrm{C}$ increments. Most of the weight loss occurred early in the 2 experiments. Water $(\sim 10 \mathrm{wt} \%)$ is lost at low temperature $\left(<200^{\circ} \mathrm{C}\right)$, followed by bone organic matter $(\sim 25 \mathrm{wt} \%)$, as shown by the rapid decrease of carbon and nitrogen contents between $100-400{ }^{\circ} \mathrm{C}$. Combustion of bone organic matter is complete between 500 and $600{ }^{\circ} \mathrm{C}$ for the 2 experiments $(<0.1 \mathrm{wt} \% \mathrm{~N})$. This transition corresponds to a change in color from black to gray. This is immediately followed by recrystallization of bone apatite, as shown by a rapid rise in CI and SF values and decrease in carbonate content between $550-650{ }^{\circ} \mathrm{C}$ and between 500 and $600{ }^{\circ} \mathrm{C}$ for Experiments A1 and A2, respectively. This transition corresponds to a change in color from gray to white. Very little (2-3 wt $\%$ ) weight is lost between 600 and $1000{ }^{\circ} \mathrm{C}$, with weight loss stabilizing at $\sim 37 \mathrm{wt} \%$. The main difference between the 2 experiments is the evolution of bone $\delta^{13} \mathrm{C}$ values. In Experiment $\mathrm{A} 1, \delta^{13} \mathrm{C}$ values decrease by $5 \%$ o between 100 and $950{ }^{\circ} \mathrm{C}$, whereas in Experiment $\mathrm{A} 2, \delta^{13} \mathrm{C}$ values remain constant.

Analytical results from Experiment B are summarized in Table 4. C and $\mathrm{N}$ contents from sample O18A indicate that bone organic matter was successfully removed at low temperature from the bone sample before cremation. Low $\mathrm{CI}$ and high $\left[\mathrm{CO}_{3}{ }^{2-}\right]$ values suggest that bone apatite structure was unaffected by heating at $450{ }^{\circ} \mathrm{C}$. Cremation (\#O18C) was found to cause a $\sim 7 \%$ decrease in $\delta^{13} \mathrm{C}$ value, associated with a $>50 \%$ decrease of bone carbonate content and an increase in CI value.

Results from Experiment $\mathrm{C}$ are summarized in Table 5. Before cremation, bone samples were beige in color and had an average $\left[\mathrm{CO}_{3}{ }^{2-}\right]$ content of $4.9 \pm 0.2 \%$ and $\delta^{13} \mathrm{C}$ value of $-16.5 \pm 0.2 \%$ o $(n=5)$. After cremation, all samples were white in color. There was only $1 / 3$ of the initial $\left[\mathrm{CO}_{3}{ }^{2-}\right]$ content left, with values ranging from 0.8 to $2.6 \% . \delta^{13} \mathrm{C}$ values of calcined bones were very variable, rang- 
Table 3 Temperature, color, remaining weight, percent of carbon and nitrogen, carbonate content, $\delta^{13} \mathrm{C}$ values, CI (XRD), and SF (FTIR) values measured on 0.5 -g aliquots of a moose jawbone (Alces alces) heated instantaneously for $1 \mathrm{hr}$ (Experiment A1), and heated progressively for $3 \mathrm{hr}$ (Experiment A2) in a programmable tubular furnace.

\begin{tabular}{|c|c|c|c|c|c|c|c|c|c|c|}
\hline Sample \# & $\begin{array}{l}\text { Time } \\
\text { (hr) }\end{array}$ & $\begin{array}{l}\mathrm{T} \\
\left({ }^{\circ} \mathrm{C}\right)\end{array}$ & Color & $\begin{array}{l}\text { Remaining } \\
\text { weight }(\%)\end{array}$ & $\begin{array}{l}\mathrm{C} \\
(\mathrm{wt} \%)\end{array}$ & $\begin{array}{l}\mathrm{N} \\
(\mathrm{wt} \%)\end{array}$ & $\begin{array}{l}{\left[\mathrm{CO}_{3}{ }^{2-}\right]} \\
(\mathrm{wt} \%)\end{array}$ & $\delta^{13} \mathrm{C}$ & CI & SF \\
\hline \multicolumn{11}{|c|}{ Experiment A1 } \\
\hline O19 & 1 & 100 & yellow & 93 & 11.9 & 3.8 & 3.8 & -15.0 & & 3.2 \\
\hline $\mathrm{O} 20$ & 1 & 200 & ocre & 89 & 12.5 & 3.8 & 3.9 & -15.4 & 0.00 & \\
\hline $\mathrm{O} 21$ & 1 & 300 & black & 72 & 4.0 & 0.9 & 7.1 & -15.7 & 0.00 & \\
\hline $\mathrm{O} 22$ & 1 & 400 & ocre-gray & 69 & 1.7 & 0.2 & 6.8 & -16.1 & 0.00 & \\
\hline $\mathrm{O} 23$ & 1 & 500 & gray & 64 & 1.3 & 0.1 & 5.5 & -16.4 & 0.13 & 3.8 \\
\hline $\mathrm{O} 24$ & 1 & 550 & gray & 68 & 1.3 & 0.1 & 4.7 & -16.6 & 0.16 & 4.0 \\
\hline $\mathrm{O} 25$ & 1 & 600 & white-gray & 64 & 0.8 & 0.1 & 3.6 & -16.3 & 0.53 & 5.6 \\
\hline $\mathrm{O} 26$ & 1 & 650 & white & 66 & 0.5 & 0.0 & 1.1 & -16.8 & 1.18 & 6.4 \\
\hline $\mathrm{O} 27$ & 1 & 700 & white & 67 & 0.4 & 0.0 & 1.2 & -17.2 & & 7.3 \\
\hline $\mathrm{O} 28$ & 1 & 750 & white & 65 & & & 1.5 & -16.8 & 1.23 & \\
\hline $\mathrm{O} 29$ & 1 & 800 & white & 65 & 0.4 & 0.1 & 1.2 & -16.9 & & 6.3 \\
\hline $\mathrm{O} 30$ & 1 & 850 & white & 63 & & & 1.1 & -17.7 & 1.28 & \\
\hline $\mathrm{O} 31$ & 1 & 900 & white & 64 & 0.3 & 0.1 & 1.0 & -18.0 & & 6.8 \\
\hline $\mathrm{O} 32$ & 1 & 950 & white & 63 & & & 0.9 & -19.9 & 1.23 & \\
\hline $\mathrm{O} 33$ & 1 & 1000 & white & 63 & 0.2 & 0.0 & & & 1.15 & 6.0 \\
\hline \multicolumn{11}{|c|}{ Experiment A2 } \\
\hline $\mathrm{O} 15$ & 3 & 100 & yellow & 92 & 11.7 & 3.7 & 4.6 & -15.1 & 0.09 & 3.2 \\
\hline $\mathrm{O} 12$ & 3 & 200 & brown/black & 79 & 8.7 & 2.4 & 4.7 & -15.3 & 0.12 & 3.4 \\
\hline $\mathrm{O} 13$ & 3 & 300 & black & 69 & 2.3 & 0.3 & 5.5 & -15.7 & & 3.5 \\
\hline $\mathrm{O} 10$ & 3 & 400 & gray/black & 71 & 1.5 & 0.2 & 5.5 & -15.0 & & \\
\hline $\mathrm{O} 7$ & 3 & 500 & white/gray & 68 & 1.2 & 0.1 & 5.3 & -15.6 & 0.27 & 4.1 \\
\hline O11 & 3 & 600 & white & 66 & 0.6 & 0.0 & 2.4 & -15.2 & 1.08 & 6.2 \\
\hline O5 & 3 & 650 & white & 66 & 0.4 & 0.0 & 1.9 & -13.8 & & \\
\hline O6 & 3 & 700 & white & 65 & 0.4 & 0.0 & & & 1.17 & 7.1 \\
\hline O8 & 3 & 800 & white & 65 & 0.3 & 0.0 & 0.9 & -14.4 & 1.22 & 10.1 \\
\hline O16 & 3 & 900 & white & 64 & 0.2 & 0.0 & 0.4 & -15.2 & 1.20 & 6.9 \\
\hline
\end{tabular}

ing from -17.0 to $-24.0 \%$. Bone samples calcined under vacuum or in the presence of $\mathrm{O}_{2}$ showed very little change in isotope values, whereas samples calcined in the presence of $\mathrm{O}_{2} / \mathrm{CO}_{2}$ showed up to $7 \%$ decrease in their $\delta^{13} \mathrm{C}$ value. The amplitude of isotope change was not correlated to the amount of $\mathrm{O}_{2}$ or $\mathrm{CO}_{2}$ present during cremation. No significant difference in $\delta^{13} \mathrm{C}$ value was found between samples calcined with tank $\mathrm{CO}_{2}(-20.4 \pm 1.7 \%$ o, $n=10)$ and samples calcined in the presence of calcite-derived $\mathrm{CO}_{2}(-19.3 \pm 0.9 \%, n=7)$.

\section{DISCUSSION}

Previous studies have shown that the exposition of bone at temperatures $>600{ }^{\circ} \mathrm{C}$ causes irreversible modifications in the crystallography, chemistry, and isotope composition of bone apatite (Shipman et al. 1984; Person et al. 1996; Munro et al. 2007; Olsen et al. 2008). Until now, only cremated bones from individuals subsisting on $\mathrm{C}_{3}$ biomass have been analyzed. We have extended the database to those relying on $\mathrm{C}_{4}$ biomass and showed that cremation can produce shifts in $\delta^{13} \mathrm{C}$ values up to $15 \%$, irrespective of the initial $\delta^{13} \mathrm{C}$ value of bone. The magnitude of the shift is highly variable within a given site, ranging, for example, from 3 to $15 \%$ at Mankhor, Algeria (Table 1). This result confirms that $\delta^{13} \mathrm{C}$ values of calcined bones are unreliable for paleoenvironmental reconstruction. Researchers should be especially aware of this bias in mixed $C_{3} / C_{4}$ environments where $C_{4}$ eaters could be mistakenly interpreted as $\mathrm{C}_{3}$ eaters. 


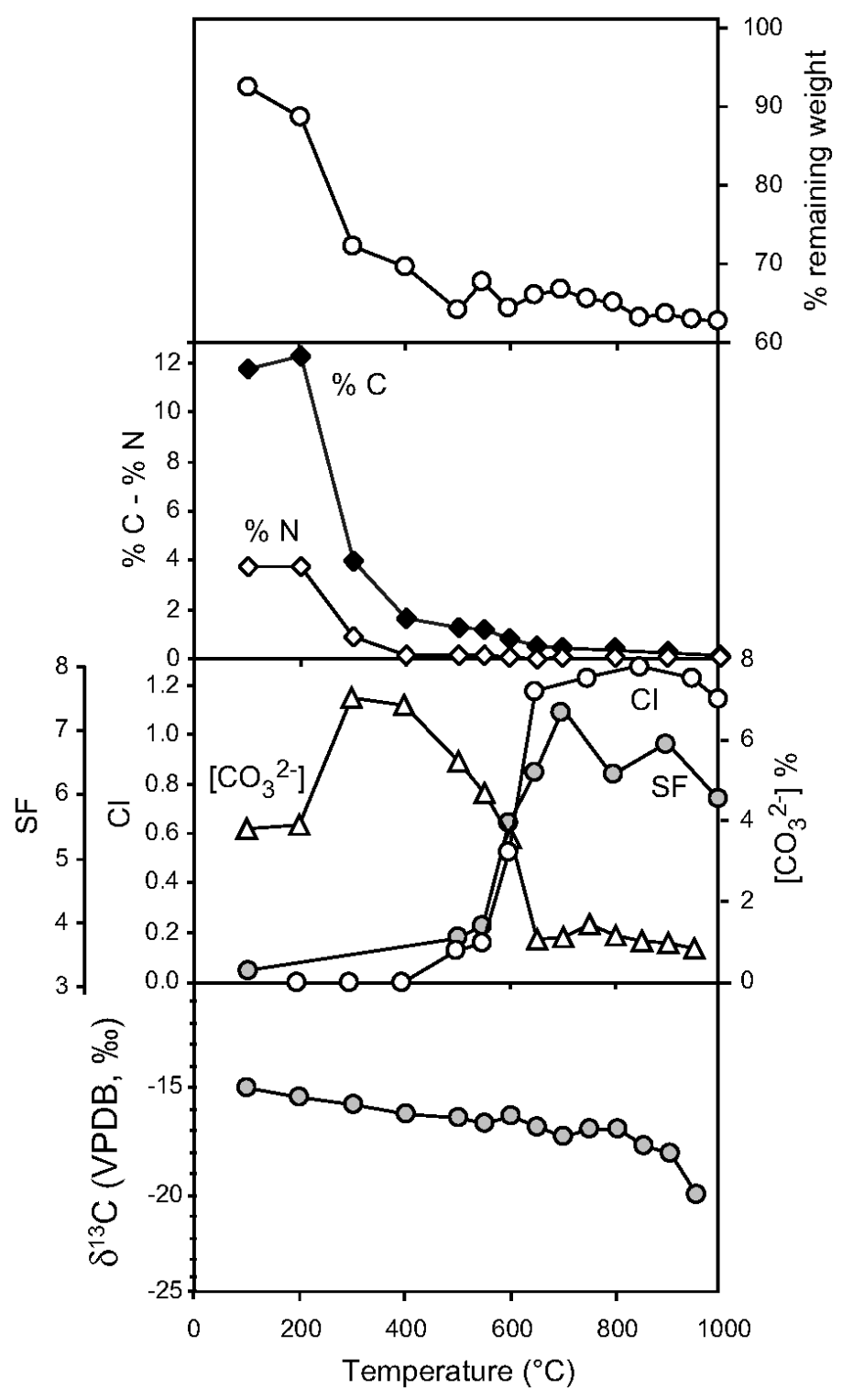

Figure 2 Results from cremation Experiment A1.

Our natural experiment on modern bones successfully reproduced the isotopic discrimination observed in archaeological assemblages between charred and calcined bones, showing that isotope change occurs very rapidly, probably during recrystallization. In order to firmly establish the reliability of ${ }^{14} \mathrm{C}$ dates obtained on calcined bone apatite, it was important to ensure that the carbon still present in calcined bones was pristine. Three different sources of carbon are potentially available for carbon exchange during combustion: bone organic matter, atmospheric $\mathrm{CO}_{2}$, and $\mathrm{CO}_{2}$ produced by the combustion of wood. 


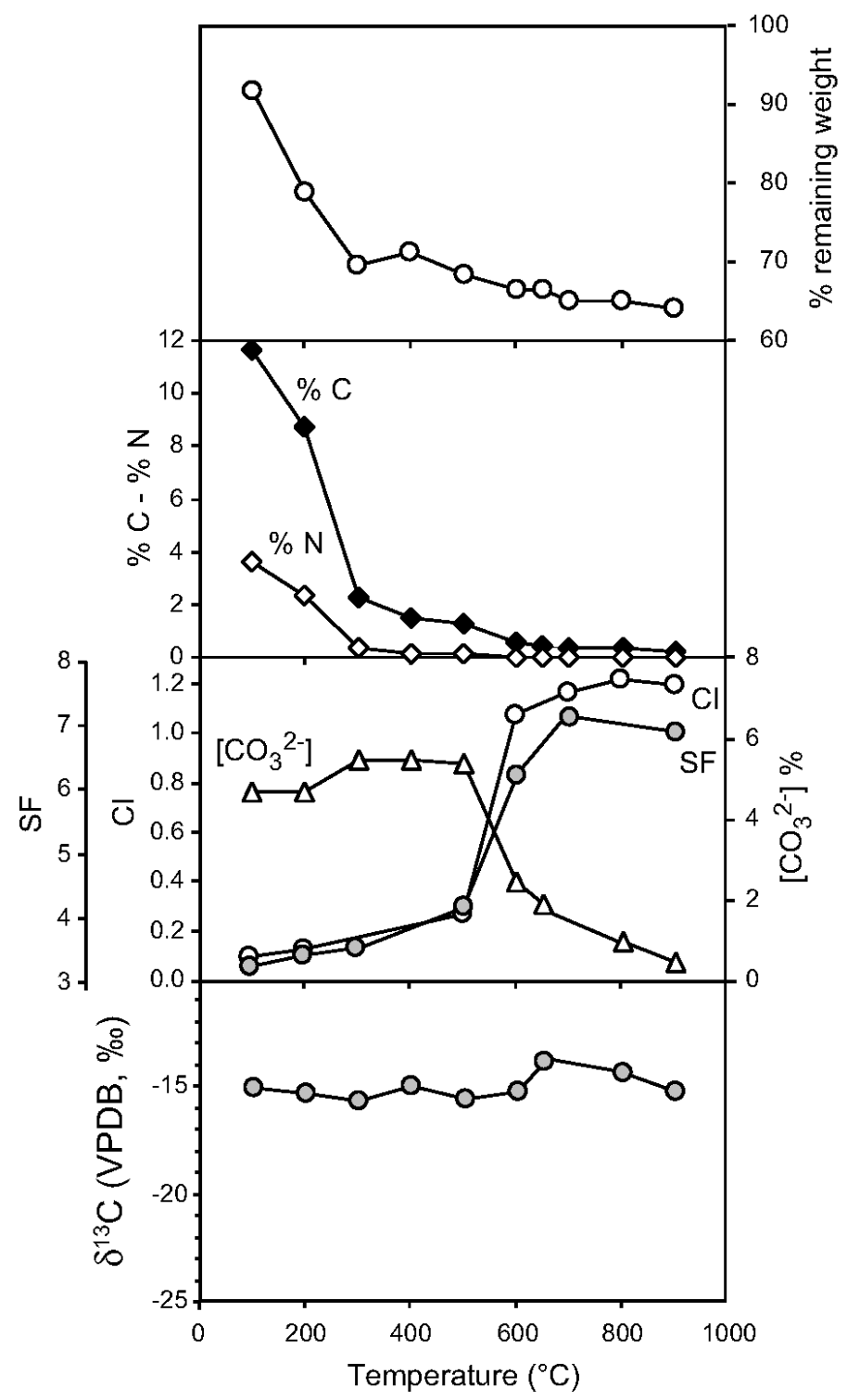

Figure 3 Results from cremation Experiment A2

Table 4 Color, percent of carbon and nitrogen, carbonate content, $\delta^{13} \mathrm{C}$, and $\mathrm{CI}$ measured on an aliquot of moose jawbone (Alces alces). Organic matter was removed in the laboratory before cremation in a fire.

\begin{tabular}{|c|c|c|c|c|c|c|c|}
\hline Sample \# & Thermal treatment & Color & $\begin{array}{l}\mathrm{C} \\
(\mathrm{wt} \%)\end{array}$ & $\begin{array}{l}\mathrm{N} \\
(\mathrm{wt} \%)\end{array}$ & $\begin{array}{l}{\left[\mathrm{CO}_{3}{ }^{2-}\right]} \\
(\mathrm{wt} \%)\end{array}$ & $\begin{array}{l}\delta^{13} \mathrm{C} \\
(\% o)\end{array}$ & $\mathrm{CI}$ \\
\hline \multicolumn{8}{|c|}{ Experiment B } \\
\hline O18A & $300{ }^{\circ} \mathrm{C}(1.5 \mathrm{hr}$, air $)+450{ }^{\circ} \mathrm{C}\left(20 \mathrm{hr}, \mathrm{O}_{2}\right)$ & ocre & 1.4 & 0.1 & 4.8 & -16.1 & 0.12 \\
\hline O18B & same as $\mathrm{O} 18 \mathrm{~A}+$ fire $(0.5 \mathrm{hr})$ & gray & & & 4.2 & -18.1 & 0.44 \\
\hline $\mathrm{O} 18 \mathrm{C}$ & same as $\mathrm{O} 18 \mathrm{~A}+$ fire $(1.0 \mathrm{hr})$ & white & & & 2.2 & -22.7 & 1.01 \\
\hline
\end{tabular}


Table 5 Composition of atmosphere during cremation, carbonate content, and $\delta^{13} \mathrm{C}$ values measured after cremation of $0.05-\mathrm{g}$ aliquots of a moose jawbone (Alces alces). Organic matter of the bone samples was removed prior cremation, using the same protocol as in Experiment B.

\begin{tabular}{|c|c|c|c|c|c|c|}
\hline \multirow[b]{2}{*}{ Sample \# } & \multicolumn{4}{|c|}{ Atmosphere during cremation } & \multicolumn{2}{|c|}{ After cremation } \\
\hline & $\begin{array}{l}\mathrm{PO}_{2} \\
\text { (mbar) }\end{array}$ & $\begin{array}{l}\mathrm{PCO}_{2}{ }^{\mathrm{a}} \\
(\mathrm{mbar})\end{array}$ & $\begin{array}{l}\mathrm{PCO}_{2}{ }^{\mathrm{b}} \\
(\mathrm{mbar})\end{array}$ & $\begin{array}{l}\text { Ptotal } \\
\text { (mbar) }\end{array}$ & $\begin{array}{l}{\left[\mathrm{CO}_{3}{ }^{2-}\right]} \\
(\mathrm{wt} \%)\end{array}$ & $\begin{array}{l}\delta^{13} \mathrm{C} \\
(\% o)\end{array}$ \\
\hline 1 & & & & $<10^{-1}$ & 2.1 & -17.0 \\
\hline 2 & 800 & & & 800 & 1.8 & -17.8 \\
\hline 3 & & 133 & & 133 & 0.9 & -18.9 \\
\hline 4 & 48 & 150 & & 198 & 2.2 & -24.0 \\
\hline 5 & 4 & 82 & & 86 & 1.3 & -18.7 \\
\hline 6 & 4 & 245 & & 249 & 2.1 & -19.8 \\
\hline 7 & 80 & 320 & & 400 & 1.7 & -20.7 \\
\hline 8 & 80 & 440 & & 520 & 1.2 & -20.9 \\
\hline 9 & 84 & 25 & & 109 & 2.6 & -20.9 \\
\hline 10 & 84 & 39 & & 123 & 2.0 & -22.1 \\
\hline 11 & 84 & 77 & & 161 & 1.8 & -20.6 \\
\hline 12 & 84 & 231 & & 315 & 2.0 & -17.9 \\
\hline 13 & 4 & & 85 & 89 & 1.1 & -18.4 \\
\hline 14 & 4 & & 231 & 235 & 1.1 & -18.9 \\
\hline 15 & 80 & & 515 & 595 & 1.2 & -18.6 \\
\hline 16 & 84 & & 25 & 109 & 2.2 & -18.4 \\
\hline 17 & 84 & & 39 & 123 & 2.0 & -21.1 \\
\hline 18 & 84 & & 77 & 161 & 0.8 & -19.9 \\
\hline 19 & 84 & & 231 & 315 & 1.8 & -19.7 \\
\hline
\end{tabular}

${ }^{\mathrm{a}} \delta^{13} \mathrm{C}_{\mathrm{CO} 2}=-41.1 \%$ VPDB.

${ }^{\mathrm{b}} \delta^{13} \mathrm{C}_{\mathrm{CO} 2}=+2.1 \%$ VPDB.

The low $\delta^{13} \mathrm{C}$ value found for a bone sample without organic matter heated in natural conditions (Experiment B) allowed us to reject bone organic matter as a potential source of carbon available to the bone apatite during recrystallization. This is in keeping with the results from Experiment A1 and A2. Step heating of bone samples shows that bone organic matter is degraded at relatively low temperature $\left(500^{\circ} \mathrm{C}\right)$, whereas the apatite structure is reorganized at $500^{\circ} \mathrm{C}$ or above, depending on the experimental conditions. Therefore, it is likely that organic carbon is no longer present when recrystallization takes place. This result confirms earlier claims that the organic phase of bone protects carbonate hydroxylapatite crystallites from external influences (Person et al. 1996).

Results from Experiment $\mathrm{C}$ show that bone $\delta^{13} \mathrm{C}$ values remained more or less stable when heated under vacuum or in the presence of oxygen. Lower $\delta^{13} \mathrm{C}$ values were measured when bone was heated in the presence of $\mathrm{CO}_{2}$ only, or $\mathrm{CO}_{2}+\mathrm{O}_{2}$, which suggests that at least 1 of these 2 gases plays a direct role in the evolution of bone apatite $\delta^{13} \mathrm{C}$ value. This experiment also showed that the amplitude of the isotope shift was not directly related to the $\mathrm{O}_{2} / \mathrm{CO}_{2}$ pressure. To confuse matters, the average $\delta^{13} \mathrm{C}$ value of bone samples calcined in the presence of 2 different sources of $\mathrm{CO}_{2}$ differing by $>40 \%$ o were not significantly different. This result strongly suggests that the low $\delta^{13} \mathrm{C}$ values measured on calcined bones are not the result of carbon isotope exchange between environmental $\mathrm{CO}_{2}$ (either from the atmosphere or from fuel combustion) and bone carbonate. Rather, we think that this is the result of a kinetic fractionation due to a high temperature gradient. This interpretation is confirmed by the different isotope profiles from Experiments A1 and $\mathrm{A} 2$. Lower $\delta^{13} \mathrm{C}$ values were measured for bone samples submitted to a high temperature gradient (A1), whereas bone samples 
submitted to a low temperature gradient (A2) remained unchanged. Although the exact mechanism remains to be discovered, we suggest that the isotopic fractionation could be related to the preferential release of the "heavy" isotopologue of the carbonate ion group ${ }^{13} \mathrm{C}^{16} \mathrm{O}_{3}{ }^{2-}$ relative to the "light" one ${ }^{12} \mathrm{C}^{16} \mathrm{O}_{3}{ }^{2-}$ during thermal stress. Each of these isotopologues has unique vibrational properties, and therefore they must differ from one another in thermodynamic stability (Schauble et al. 2006). Given the large difference in abundance between the 2 isotopologues $\left(1.1 \%\right.$ for ${ }^{13} \mathrm{C}^{16} \mathrm{O}_{3}{ }^{2-}$ vs. $98.2 \%$ for ${ }^{12} \mathrm{C}^{16} \mathrm{O}_{3}{ }^{2}$ ), even a subtle difference in their behavior could leave the remaining stock of carbonates depleted in ${ }^{13} \mathrm{C}$ relative to the carbonate initially present in the bone.

We must note, however, that the $\delta^{13} \mathrm{C}$ values obtained from bones calcined in the laboratory are not as low as the values measured on modern or archaeological bones calcined in natural conditions. This discrepancy suggests that the experimental conditions do not exactly reproduce the natural conditions. Therefore, we cannot totally exclude the possibility of some sort of chemical exchange/ addition between fuel carbon and apatite during cremation. A possible test would be to combust modern bones in the presence of $\mathrm{C}_{4}$ plants (e.g. palm trees) instead of $\mathrm{C}_{3}$ plants. Further research will be required to fully resolve this issue.

\section{CONCLUSIONS}

New data from archaeological sites confirm that calcined bones are unreliable for paleoenvironmental and paleodietary reconstruction using stable isotopes. Unrealistic $\delta^{13} \mathrm{C}$ values are easily detected in $\mathrm{C}_{3}$ environments. In contrast, archaeologists should be cautious in mixed $\mathrm{C}_{3} / \mathrm{C}_{4}$ environments where $\mathrm{C}_{4}$ eaters could be mistakenly interpreted as $\mathrm{C}_{3}$ eaters. By following an experimental approach, we have shown that the low $\delta^{13} \mathrm{C}$ values measured on calcined bones can be explained by kinetic effects. Even though carbon exchange between apatite and wood during cremation cannot be totally excluded, what we measure in a calcined bone is essentially the remaining fraction of carbonate initially present in the bone and highly fractionated during cremation. Therefore, the reliability of the calcined portion of bones for ${ }^{14} \mathrm{C}$ dating should be seen as close to that of tooth enamel due to the recrystallization of bone apatite at high temperature.

\section{ACKNOWLEDGMENTS}

We are indebted to various people for providing the archaeological and modern samples used in this study: F Paris for the samples from Chin Tafidet, G Aumassip for the samples from Mankhor, L Bachelot for the samples from Tell Shiukh Fawqani, and R Rubiletz and T Prokopiuk for providing and preparing the moose sample. We would also like to thank M Mandeng-Yogo and F Cetin (IRD, Bondy) for their assistance with the $\mathrm{C}$ and $\mathrm{N}$ measurements and $\mathrm{R}$ Bendrey for checking the English. We extend our gratitude to the Dufour and the Peigné families for giving us access to their fireplace. Finally, we would like to thank Irka Hajdas and the organizing committee of the 5th Radiocarbon and Archaeology conference in Zurich, for giving us the opportunity to present these results.

\section{REFERENCES}

Balter V, Saliège JF, Bocherens H, Person A. 2002. Evidence of physico-chemical and isotopic modifications in archaeological bones during controlled acid etching Archaeometry 44(3):329-36.

Bertaux J, Fröhlich F, Ildefonse P. 1998. Multicomponent analysis of FTIR spectra: quantification of amorphous and crystallized mineral phases in synthetic and natural sediments. Journal of Sedimentary Research 68(3): 440-7.
Bronk Ramsey C, Higham TFG, Bowles A, Hedges REM. 2004. Improvements to the pretreatment of bone at Oxford. Radiocarbon 46(1):155-63.

Hassan AA, Termine JD, Haynes Jr CV. 1977. Mineralogical studies on bone apatite and their implications for radiocarbon dating. Radiocarbon 19(3):364-74.

Haynes Jr CV. 1968. Radiocarbon: analysis of inorganic carbon of fossil bone and enamel. Science 161(3842): 687-88. 
Higham TFG, Jacobi RM, Bronk Ramsey C. 2006. AMS radiocarbon dating of ancient bone using ultrafiltration. Radiocarbon 48(2):179-95.

Hüls MC, Grootes PM, Nadeau MJ. 2007. How clean is ultrafiltration cleaning of bone collagen? Radiocarbon 49(2): 193-200.

Lanting JN, Aerts-Bijma, AT, van der Plicht J. 2001. Dating cremated bone. Radiocarbon 43(2A):249-54.

Munro LE, Longstaffe J, White CD. 2007. Burning and boiling of modern deer bone: effects on crystallinity and oxygen isotope composition of bioapatite phosphate. Palaeogeography, Palaeoclimatology, Palaeoecology 249(1-2):90-102.

Munro LE, Longstaffe J, White CD. 2008. Effects of heating on the carbon and oxygen-isotope compositions of structural carbonate in bioapatite from modern deer bone. Palaeogeography, Palaeoclimatology, Palaeoecology 266(3-4):142-50.

Olsen J, Heinemeier J, Bennike P, Krause C, Hornstrup KM, Thrane H. 2008. Characterisation and blind testing of radiocarbon dating of cremated bone. Journal of Archaeological Science 35(3):791-800.

Person A, Bocherens H, Saliège JF, Zeitoun V, Gérard M. 1995. Early diagenetic evolution of bone phosphate: an X-ray diffractometry analysis. Journal of Archaeological Science 22(2):211-21.
Person A, Bocherens H, Mariotti A, Renard M. 1996. Diagenetic evolution and experimental heating of bone phosphate. Palaeogeography, Palaeoclimatology, Palaeoecology 126(1-2):135-49.

Saliège JF, Person A, Paris F. 1995. Preservation of ${ }^{12} \mathrm{C} /$ ${ }^{13} \mathrm{C}$ original ratio and ${ }^{14} \mathrm{C}$ dating of the mineral fraction of human bones from Saharan tombs, Niger. Journal of Archaeological Science 22(2):301-12.

Schauble EA, Ghosh P, Eiler J. 2006. Preferential formation of ${ }^{13} \mathrm{C}-{ }^{18} \mathrm{O}$ bonds in carbonate minerals, estimated using first principle lattice dynamics. Geochimica et Cosmochimica Acta 70(10):2510-29.

Schoeninger MJ, DeNiro MJ. 1982. Carbon isotope ratios of apatite from bone cannot be used to reconstruct diets of animals. Nature 297(5867):577-8.

Shemesh A. 1990. Crystallinity and diagenesis of sedimentary apatites. Geochimica et Cosmochimica Acta 54(9):2433-38.

Shipman P, Foster G, Schoeninger M. 1984. Burnt bones and teeth: an experimental study of color, morphology, crystal structure and shrinkage. Journal of Archaeological Science 11(4):307-25.

Van Strydonck M, Boudin M, Hoefkens M, De Mulder G. 2005. ${ }^{14} \mathrm{C}$ dating of cremated bones, why does it work? Lunula 13:3-10. Online at https://archive.ugent.be/retrieve/3095/14C-analyseLunulaXIII.pdf. 